\title{
Políticas públicas do setor energético renovável no Estado da Paraíba (Nordeste do Brasil): limitações legislativas, entraves técnicos e perspectivas regulamentares
}

\section{Edvanil Albuquerque Duarte Junior ${ }^{1}$, Raimundo Aprígio de Menezes $^{2}$, Charlie Salvador Gonçalves ${ }^{3}$ e Edson Ramos de Andrade ${ }^{3}$}

\begin{abstract}
${ }^{1}$ Universidade Federal da Paraíba. Centro de Ciências Exatas e da Natureza. Programa de Pós-Graduação em Desenvolvimento e Meio ambiente. Campus I. João Pessoa-PB, Brasil (CEP 58051-900). E-mail: edvaniljr@gmail.com.

${ }^{2}$ Universidade Federal da Paraíba. Centro de Energias Alternativas e Renováveis. Departamento de Engenharia de Energias Renováveis. Campus I. João Pessoa-PB, Brasil (CEP 58051-900).

${ }^{3}$ Universidade Federal da Paraíba. Centro de Ciências Exatas e da Natureza. Departamento de Física. Campus I. João Pessoa-PB, Brasil (CEP 58051-900).
\end{abstract}

Resumo. A tendência global de buscar fontes renováveis de geração de energia elétrica como alternativa para o gradual aumento da demanda energética é latente. No Brasil não é diferente, por encontrar-se em processo de diversificação de sua matriz energética. As políticas públicas brasileiras de fomento à geração de energia renovável multimatrizes não contam com forte presença estatal, como no modelo chinês. Também não possuem foco em parcerias público-privadas, como nos modelos estadunidense e europeu. A legislação nacional apenas traça normas gerais como norte, a estados e municípios, quanto à elaboração de projetos que atendam às suas necessidades. A legislação do Estado da Paraíba, um dos estados da Região Nordeste do Brasil, falha ao instituir por meio de duas leis, uma política de fomento à utilização de energia solar e eólica, principalmente por não conceder benefícios fiscais e tributários para a energia eólica. A legislação pernambucana, em seu turno, demonstra relação direta entre objetivos normatizados e medidas necessárias à concretização dos projetos. Diante disso, o objetivo geral da pesquisa visa, a partir do modelo nacional de estímulo à geração de energia renovável, a estudar a fragilidade legislativa do Estado da Paraíba em relação à utilização das matrizes energéticas renováveis solar e eólica. A pesquisa foi realizada através do método bibliográfico, com foco em doutrina, legislação e periódicos das áreas jurídica, legislativa e energética. 0 principal resultado aponta para a necessidade de elaboração de projetos de leis que incorporem a geração de energia renovável à rotina diária de empresas e do cidadão, como forma de reforçar o
Recebido

$17 / 12 / 2020$

Aceito

$30 / 03 / 2021$

Disponível on line 04/04/2021

Publicado 30/04/2021

Acesso aberto

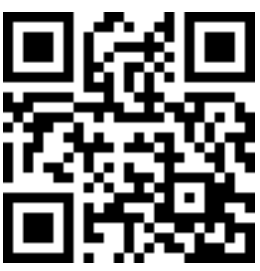

ORCID

D 0000-0002-8202-4238 Edvanil Albuquerque Duarte Junior

ISSN 2359-1412/RBGAS-2020-0179/2021/8/18/6/107

Rev. Bras. Gest. Amb. Sustent.

http://revista.ecogestaobrasil.net 
elo entre a normatização da matéria, a demonstração da necessidade social e sua implementação, conduzindo o poder público ao atendimento dos interesses da coletividade.

Palavras-chave: Diversificação energética; Energia renovável; Políticas públicas; Entraves legislativos; Fragilidade legal; Setor energético renovável.

Abstract. Public policies for the renewable energy sector in the
State of Paraíba (Northeast Brazil): Legislative limitations,
technical barriers and regulatory perspectives. The global trend to seek electricity generation renewable sources as an alternative to the gradual increase in energy demand is latent. It is no different in Brazil, since it is in the process of diversifying its energy matrix. Brazilian public policies to promote multi-matrix renewable energy do not have a strong state presence, as in the Chinese model. Nor are they focused on public-private partnerships, as in the American and European models. National legislation only outlines general norms such as the guidelines for states and municipalities, regarding projects that meet their needs. The legislation of the State of Paraíba, one of the states in the Northeast of Brazil, fails to institute, through two laws, a policy to promote the use of solar and wind energy, without granting tax benefits for wind energy. The legislation in Pernambuco, a state also located in the Northeast Region of Brazil, demonstrates a direct relationship between standardized objectives and measures necessary for carrying out the projects. Given this, the general objective of the research aims, based on the national model of stimulating the generation of renewable energy, to study the legislative weakness of the State of Paraíba in relation to the use of renewable solar and wind energy matrices. The research was carried out using the bibliographic method, focusing on doctrine, legislation and journals in the legal, legislative and energy areas. The main result points to the need to draft laws that incorporate the generation of renewable energy into the daily routine of companies and citizens, as a way of reinforcing the link between the standardization of the matter, the demonstration of social need and its implementation, leading the public authorities to serving the community interests.

Keywords: Energetic diversification; Renewable energy; Public policy; Legislative barriers; Legal weakness; Renewable energy.

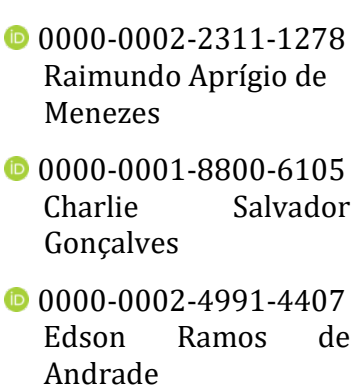

\section{Introdução}

A tendência de utilização de fontes renováveis de geração de energia elétrica vem propagando-se em todo o planeta. A busca por matriz(es) energética(s) mais limpa(s) e com menor impacto ambiental, também é tendência atual no Brasil (Hinrichs et al., 2014), que possui modelo fundado na utilização em larga escala de combustíveis fósseis e em hidrelétricas de grande porte, ganhando força a cada nova campanha de conscientização a 
respeito da necessidade do uso/adoção de energias renováveis, menos danosas ao meio ambiente e, tanto quanto possível, mais eficientes.

Conforme estudo da Fundação Brasileira para o Desenvolvimento Sustentável (FBDS, 2018), a transição para um futuro de energia sustentável visando à compatibilidade com a preservação da integridade dos recursos naturais, trata-se de um dos grandes desafios para a humanidade neste século. A existência de profissionais preparados, de legislação atualizada e de planejamento urbano, faz com que perspectivas otimistas sejam traçadas acerca do crescimento na utilização das fontes energéticas de baixo nível de poluição.

No último quadriênio, Projeto de Lei do Senado Federal no 107/2017, trata da matéria, com enfoque em favorecer empreendimentos que produzam energia elétrica com mais de um tipo de fonte renovável, dispondo, em sua ementa, acerca da inclusão "no ambiente de contratação regulada, processos licitatórios de energia elétrica produzida em empreendimentos com mais de um tipo de fonte renovável de geração" (Brasil, 2017).

Projetos de ampliação do espectro de geração de energias limpas viabilizam a redução, a médio e longo prazo, da emissão e concentração de partículas gasosas nocivas na atmosfera, que agravam o efeito estufa, muito impactado por algumas fontes energéticas, a exemplo das usinas termelétricas. Também há que se considerar a preservação de recursos naturais, como as paisagens e ecossistemas naturais, os cursos de rios, as alterações em longas áreas impactadas pela implementação, por exemplo, de uma usina de geração de energia hidráulica.

Diante desse contexto, estudos a respeito da matéria mostram-se primordiais para se entender as razões pelas quais a expansão do uso de fontes de geração energética oriundas de fontes renováveis, aliada a todos os benefícios dela decorrentes (otimização dos processos produtivos, barateamento da tecnologia envolvida, redução nas emissões de gases e de resíduos poluentes, preservação de ecossistemas etc.) ainda esbarram em marcos regulamentares pouco eficientes, quando o assunto é o estímulo ao setor através de políticas públicas.

Ocorre que, doravante a latente necessidade de fomento aos programas com viés econômico e tecnológico, em prol da sociedade, sem abrir mão da conservação dos aspectos ambientais, os marcos regulamentares nacionais afiguram-se, em regra, demasiadamente genéricos. Exemplo desta realidade é a legislação em matéria energética renovável existente no Estado da Paraíba, objeto central da análise, que demonstra fragilidade programática e nítido direcionamento finalístico a apenas um modelo econômico de fomento à energia renovável.

Desse modo, o objetivo geral desta pesquisa visa a avaliar as potencialidades, os entraves legais e regulamentares, bem como as perspectivas que envolvem as políticas públicas voltadas para o incentivo ao uso das fontes renováveis de geração de energia elétrica, em nível nacional e, especialmente, estudar o caso de fragilidade legislativa que envolve as leis que fomentam as políticas públicas para a utilização de energia elétrica de origem renovável no Estado da Paraíba.

\section{Políticas públicas do setor energético renovável em nível mundial}

Em nível global e em análise sintética, utilizaremos como parâmetro de amostragem a China, os Estados Unidos da América e a Europa (países componentes da União Europeia), destacando suas matrizes energéticas predominantes e as políticas públicas para o setor de energias renováveis.

A China, além de possuir fortes investimentos em seu território, também investe em outros países, a exemplo da construção de plantas eólicas no polo norte, da participação no consórcio que visa a ligar a Usina de Belo Monte, no Xingu-PA, à 
Subestação de Estreito no Município de Ibiraci-MG, bem como do megaprojeto Global Energy Interconnection - GEI (CEIRI NEWS, 2018), estimado em 50 trilhões de dólares.

As políticas públicas adotadas pelos EUA e União Europeia também se afiguram distintas do modelo chinês, em que o governo incentiva universidades e empresas privadas a produzirem em larga escala, fomentando emprego e renda e, como contrapartida, concede benefícios financeiros e fiscais. Nesse modelo, gera-se um círculo virtuoso em termos econômicos e energéticos, em diversos aspectos, mesmo considerado os efeitos da redução na arrecadação (Carvalho, 2019).

Quanto às experiências internacionais envolvendo as parcerias público-privadas, Carvalho Filho (2010), tece as seguintes considerações:

\begin{abstract}
As parcerias público-privadas têm sido adotadas com sucesso em diversos ordenamentos jurídicos, como, entre outros, os de Portugal, Espanha, Inglaterra e Irlanda, e apresentam como justificativa dois pontos fundamentais, sobretudo em relação aos países ainda em desenvolvimento: a falta de disponibilidade de recursos financeiros e a eficiência de gestão do setor privado" (Carvalho Filho, 2010, p. 461.)
\end{abstract}

Assim, as parcerias público-privadas (PPPs) surgem como solução, eis que o setor público, mesmo sem capital, ou sem lastro para tomar empréstimos, pode realizar obras necessárias a garantir direitos fundamentais inadiáveis da população, a exemplo de PPP entre o Governo Federal e empresa privada do setor energético para a construção de hidrelétrica de grande capacidade instalada de produção, para atender a demanda de energia de determinada parte do território nacional.

Os investimentos oriundos do capital privado atendem necessidade pública premente e, em contrapartida, conta com a permissão Estatal para explorar a atividade econômica vinculada à comercialização da produção energética, com a redução ou até com a isenção fiscal por determinado prazo (EUR-LEX, 2015).

Exemplo bem-sucedido de política pública é o movimento " $100 \%$ Renewable Energy" que ganhou destaque especial após a conferência sobre clima COP21, realizada em 2015, na capital francesa. Essa política visa ao comprometimento em alcançar a implementação de sistema energético 100\% renovável, em todos os setores das cidades aderentes, Coffs Harbour, Byron Shire e Uralla, na Austrália, Vancouver e Oxford County, no Canadá, tal como as cidades estadunidenses San Diego, na Califórnia, e Rochester, em Minnesota.

\title{
Políticas públicas do setor energético renovável em nível nacional
}

No Brasil, compete à União, de forma privativa, legislar em matéria de energia (Brasil, 1988). Contudo, Estados e Municípios podem elaborar políticas públicas com regulamentações voltadas à geração de energia elétrica. No caso dos governos estaduais e municipais, a tônica continua sendo a concessão de benefícios fiscais para geração e uso. Em âmbito federal, infelizmente, o foco continua sendo o de leiloar, por parte do Governo Federal, potencial de produção energética para o setor privado, que passa a explorar a atividade por décadas.

Os leilões são espécie de política regulatória em que autoridades públicas ou empresas concessionárias do ramo de energia elétrica preparam certame com objetivo de alcançar volume de energia capaz de suprir a necessidade do mercado. Os valores são definidos de acordo com as ofertas dos participantes e os contratos possuem prazos determinados (em média dez, vinte, trinta anos), com garantia de compra de todo o montante contratado (Brasil, 2006). 
A União em vez de focar em leilão de geração e também na concessão de incentivos tributários (créditos fiscais, isenções, deduções e reduções de alíquotas), poderia priorizar a realização de parcerias público-privadas para fomentar, em larga escala, o uso das energias renováveis.

Em termos de políticas públicas que fomentem a energia renovável em nível nacional, destaca-se que o modelo brasileiro não conta com a forte presença estatal, liberando ampla gama de recursos para elaboração e construção de usinas de geração renovável multimatrizes em seu território, bem como em outros países, como se verifica no modelo chinês. Também não se assemelha ao modelo estadunidense e europeu, com foco em parcerias público-privadas (PPP) para o estudo e a implementação de projetos no setor. Na verdade, as políticas públicas brasileiras, em termos de geração energética, não são vastas, tampouco específicas e detalhadas.

Por meio do Plano Nacional de Energia 2030 (Brasil, 2007), relatório elaborado pelo Ministério de Minas e Energia (MME), torna-se possível o planejamento acerca do suprimento energético para as próximas décadas. 0 não menos importante relatório “Matriz Energética Nacional 2030" (Brasil, 2007), figura ao lado do PNE 2030, sendo eles as principais ferramentas de planejamento de longo prazo disponível aos gestores públicos e também ao setor privado (Figura 1).

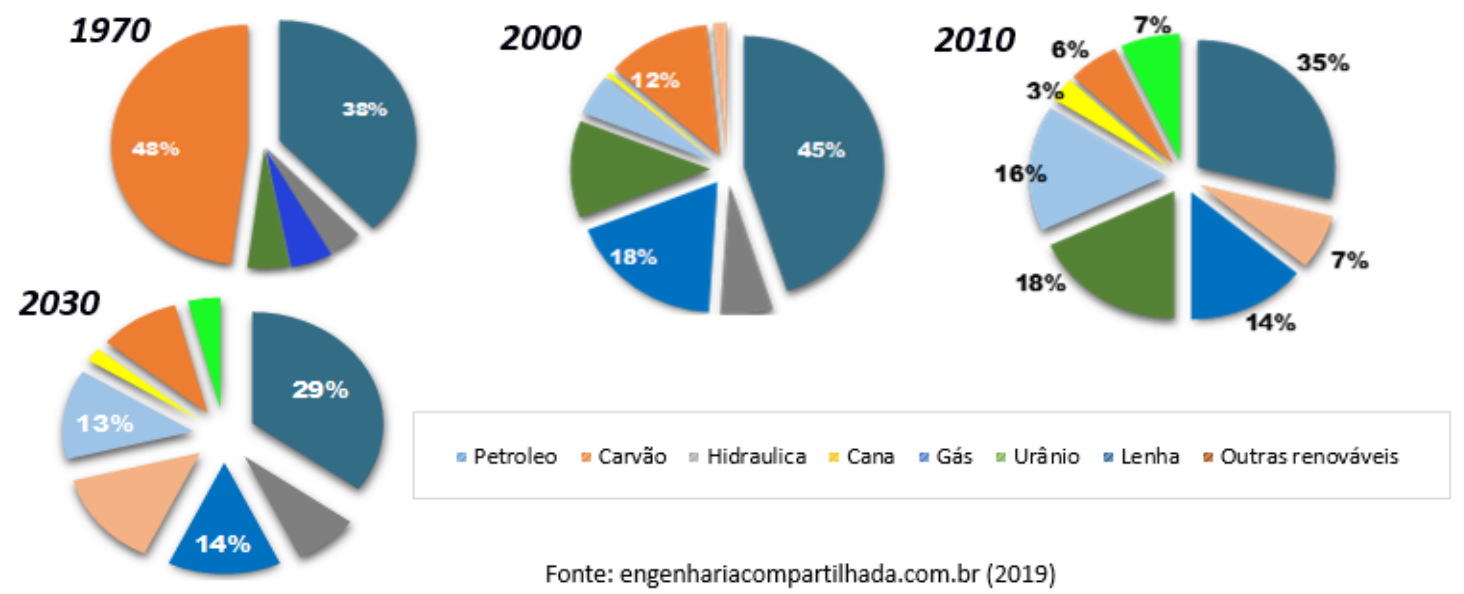

Figura 1. Balanço energético, em gráficos de 30 anos, de 1970 a 2030.

Em relação à legislação sobre políticas energéticas, são duas as regulamentações que mais se destacam em cenário nacional. A Lei no 12.187/2009 (Brasil, 2009), que institui a Política Nacional sobre Mudanças do Clima (PNMC), a qual sua regulamentação (Decreto no 7.390/2010) é utópica, generalista e não prevê sanções, tratando-se de norma programática que estabelece os princípios, os objetivos, as diretrizes e os instrumentos necessários à implantação da PNMC.

A outra normatização de destaque é a Resolução Normativa ANEEL no 482/2012 (Brasil, 2012), atualizada pela Resolução Normativa ANEEL no 687/2015 (Brasil, 2015), que estabelece as condições gerais para o acesso de micro geração e mini geração distribuída aos sistemas de distribuição de energia elétrica e ao sistema de compensação de energia elétrica. Estas resoluções disciplinam a possibilidade de geração de sua própria energia pelo consumidor brasileiro, a partir de fontes renováveis, ou de cogeração qualificada, além da possibilidade de fornecer o excedente para a rede de distribuição 
local. Trata-se, portanto, de regulamentação acerca da micro e da minigeração distribuídas de energia elétrica.

Merece destaque, ainda, o estimulo governamental aos veículos híbridos/elétricos, que favorece indiretamente o setor de energias renováveis.

Em junho de 2019, foi derrubado o veto presidencial no 40/2018 ao trecho do art.

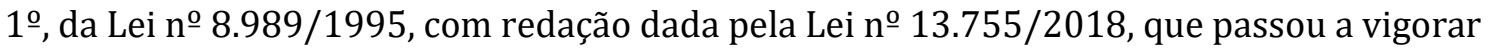
com a dispensa do Imposto sobre Produtos Importados (IPI), que incidia sobre compra e venda de veículos híbridos e elétricos fabricados no país e de potência limite de $2.000 \mathrm{~cm}^{3}$, também isentando o setor de autopeças desses segmentos da taxação federal (Brasil, 2018a).

0 incentivo fiscal beneficia motoristas profissionais, permissionárias ou concessionárias de transporte público, portadores de necessidades especiais e beneficiários do Projeto Balcão de Ferramentas.

Esta, dentre outras adequações legislativas, surgiu como forma de fomentar o Programa Rota 2030, instituído por meio da Medida Provisória no 843/2018, convertida para a Lei $n^{0} 13.755 / 2018$, cujo objetivo principal é a busca pelo aprimoramento das políticas públicas voltadas para os setores de mobilidade, logística e transporte.

Trata-se de renúncia fiscal federal que pode chegar na ordem de bilhões de reais até 2025. No entanto, os benefícios por ela trazidos são exponencialmente superiores à cifra não arrecadada imediatamente pelo Governo Federal, eis que o estímulo à fabricação de veículos e autopeças, às concessões de rodovias que geram crédito extraordinário, a produção em massa de componentes vinculados à geração e ao armazenamento de energias renováveis, por exemplo, aquecem a economia, proporciona a geração de emprego e renda e chama atenção dos investidores quanto ao potencial da indústria nacional (Brasil, 2018b).

0 crescente estímulo governamental aos veículos elétricos e híbridos, fomenta a implementação de cadeia de produtos e serviços em benefício do setor, a exemplo da empresa do setor elétrico Energias de Portugal-Brasil, que anunciou plano para implantação de 30 eletropostos de abastecimento automotivo com geração da energia elétrica por meio da matriz fotovoltaica, cobrindo todo o estado de São Paulo, sendo disponibilizados a cada $150 \mathrm{~km}$, ao custo de R \$32,9 milhões e com prazo final para 2022 (Portal Solar, 2019).

\section{Programas de fomento ambiental envolvendo energias renováveis no Estado da Paraíba}

No cenário do Estado da Paraíba, em termos de regulamentação normativa, verifica-se que através da Resolução no 16/2015, do Conselho Superior de Ensino, Pesquisa e Extensão (COSEPE), da Universidade Federal da Paraíba (UFPB), foi criado o Curso de Graduação em Engenharia de Energias Renováveis, pelo Centro de Energias Alternativas e Renováveis (CEAR). Essa graduação visa a capacitar os alunos "para absorver e desenvolver novas tecnologias, estimulando-os para atuação crítica e criativa na identificação e resolução de problemas, considerando seus aspectos políticos, econômicos, sociais, ambientais e culturais, com visão ética e humanística, em atendimento às demandas da sociedade" (UFPB, 2015, p. 4).

A UFPB ainda conta com o estudo e a produção científica de soluções voltadas para a criação e a implementação de tecnologias ligadas às energias renováveis por meio do CEAR, do Centro de Ciências Exatas e da Natureza (CCEN) e do Programa de PósGraduação em Desenvolvimento e Meio Ambiente (PRODEMA). Ressalta-se que os projetos desenvolvidos nestes setores não giram apenas em torno dos badalados proveitos econômicos e tecnológicos decorrente da utilização das fontes renováveis de geração de energia e, principalmente, mantém firme o foco no benefício ao meio ambiente, 
consubstanciado pela redução do risco de desastres ambientais e da forte pegada ecológica presente em outras fontes de geração de energia amplamente utilizadas no país, a exemplo de hidrelétricas, termelétricas e nucleares.

Em maior escala, a Lei no 10.718/2016, dispõe sobre "a obrigatoriedade de instalação de sistemas de captação de energia solar na construção de novos prédios, centros comercias e condomínios residenciais" (Paraíba, 2016, p. 2). A legislação, em seu art. $3^{3}$, preceitua que todo projeto de construção predial, comercial e residencial, deverá instalar sistema de captação, de armazenamento e de utilização da energia solar, com dimensionamento capaz de cobrir, ao menos, 30\% da demanda mínima anual de energia elétrica (Paraíba, 2016a).

Colaferro (2018) apurou os dados estatísticos (até dezembro de 2018) dos estados em que os sistemas fotovoltaicos mais ganham espaço entre os telhados dos consumidores e elaborou ranking com o número absoluto de sistemas em cada território, além da divisão de sistemas (comercial, residencial, rural e outros), a participação percentual em relação ao número nacional e também o número de empresas que fornecem produtos e serviços do setor de energias renováveis. O Estado da Paraíba ficou em 15을 lugar, dentre os 27 estados da Federação, constatando o déficit de incentivo ao setor (Figura 2) (Colaferro, 2018).

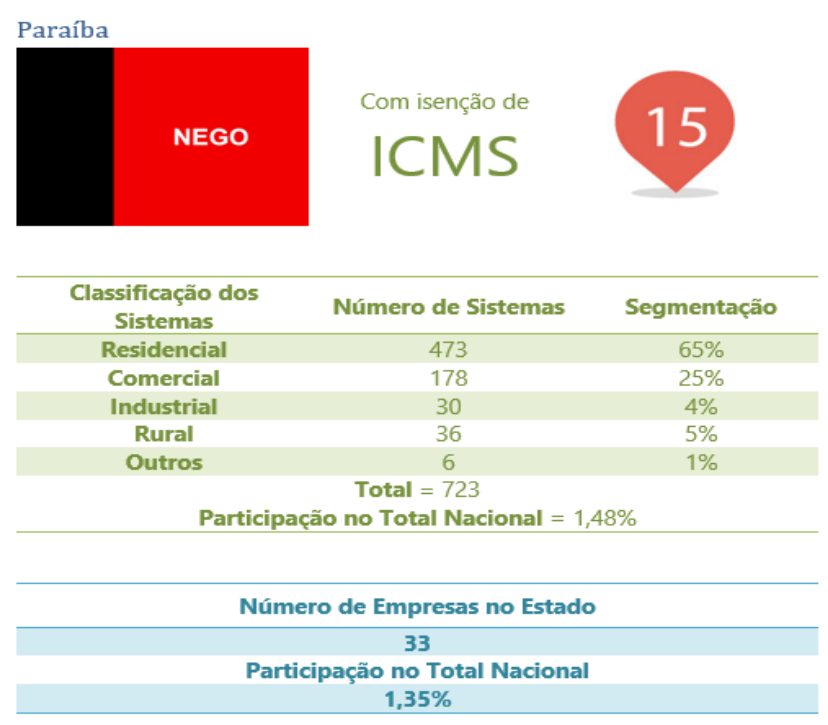

Figura 2. Ranking nacional de evolução na utilização de painéis fotovoltaicos. Fonte: Colaferro (2018).

A Lei no 10.720/2016 atualiza e amplia a legislação que dispõe sobre a matéria e institui a "política estadual de incentivo à geração e aproveitamento de energia solar e eólica" no Estado da Paraíba por meio de créditos de ICMS para estabelecimento industrial que utilize essa fonte (Paraíba, 2016b, art. 5, III).

Fragilidades da legislação que regulamenta os programas de energias renováveis no Estado da Paraíba

Como visto, fora os programas de fomento ambiental envolvendo energias renováveis implementados no âmbito da Universidade Federal da Paraíba (UFPB), de 
menor escala, o Estado da Paraíba possui duas leis voltadas especificamente para a implementação de tecnologias de geração de energia renovável fotovoltaica e eólica.

A Lei no 10.718/2016 determina que novos prédios, centros comerciais e condomínios residenciais instalem sistemas de captação de energia solar (Paraíba, 2016a). Por sua vez, a Lei no 10.720/2016, atualiza e amplia a legislação acerca da matéria, também tratando da utilização de créditos de Imposto sobre Circulação de Mercadorias e prestação de Serviços (ICMS) para estabelecimentos industriais que utilizarem as energias solar e eólica (Paraíba, 2016b).

No entanto, apesar da Lei no 10.720/2016 propor atualizar e ampliar a implementação prática das tecnologias renováveis de geração de energia elétrica, inicialmente tratada pela Lei no $10.718 / 2016$, a redação pela Lei no $10.720 / 2016$, que inclui o setor industrial no espectro de incentivo fiscal e tributário para fomento e utilização de energias renováveis solar e eólica, cria discrepâncias em relação à priorização do modelo de geração solar.

Em seu art. 3o, incisos X a XIII, ao tratar das responsabilidades do estado quanto à implementação das políticas programadas, a Lei no 10.720/2016 trata do financiamento de ações, pesquisas e estudos para implementação prática, além da concessão de benefícios fiscais e tributários, direcionando atenção "especial da energia solar" (Paraíba, 2016b).

No art. 5으, III, a Lei no 10.720/2016, que trata do incentivo fiscal e tributário, da pesquisa tecnológica, da assistência técnica e da promoção dos produtos, a legislação não apenas prioriza a geração de energia solar, como sequer elenca a geração de energia eólica como atividade que bonificaria estabelecimentos industriais por meio de crédito presumido em ICMS: "O estabelecimento industrial que adquirir energia elétrica de fonte renovável solar deverá ser estimulado mediante a concessão de crédito presumido do ICMS, na forma do decreto de regulamentação da lei" (Paraíba, 2016b).

Da análise detida das legislações estaduais da Paraíba que tratam do incentivo à geração de energias renováveis de fontes solar e eólica por meio da concessão de incentivos fiscais e tributários, percebe-se o nítido direcionamento de privilégios estatais a um único modelo de geração, o fotovoltaico.

A Lei no 10.718/2016 regulamenta a obrigatoriedade de instalação de sistemas de captação de energia solar na construção de novos prédios comerciais e condomínios residenciais no Estado (Paraíba, 2016a). A Lei no 10.720/2016, a seu turno, oferta aos estabelecimentos industriais a concessão de créditos de ICMS para os que adquirirem energia elétrica de fonte renovável solar. 0 intuito do legislador, além da limitação ao modelo fotovoltaico, sequer foi o de incentivo direto à pesquisa, desenvolvimento e geração de energia renovável, mas tão somente o de conceder benefício fiscal e tributário para a indústria que "adquirir energia elétrica de fonte renovável solar" (Paraíba, 2016b).

Verifica-se, dessa forma, a existência de inconsistências na regulamentação legislativa das normas programáticas de incentivo à pesquisa e à implementação de tecnologias de geração de energia elétrica por meio de fontes renováveis, bem como a forte presença de direcionamento dos incentivos fiscais/tributários para o modelo fotovoltaico.

\section{Estudo comparado entre as legislações paraibana e pernambucana de fomento ao uso de energia fotovoltaica através da concessão de crédito presumido de ICMS}

O Decreto no 39.460/2013 regulamenta a concessão e a utilização do crédito presumido do ICMS do Programa de Sustentabilidade na Atividade Produtiva (PESUSTENTÁVEL), instituído pela Lei no 14.666/2012 (Pernambuco, 2013).

Os arts. 1ㅁ, $2^{o}$ e $8^{\circ}$ deste Decreto (no 39.460/2013) disciplinam que o estabelecimento industrial que adquirir energia elétrica de fonte renovável solar pode ser 
estimulado mediante a concessão de crédito presumido do ICMS, detalhando os critérios a serem preenchidos para a percepção do incentivo fiscal e tributário.

0 Decreto no 14.876/1991 apenas beneficiava a indústria eólica. As complementações feitas por meio do Decreto no 42.034/2015, estendeu os benefícios fiscais e tributários para a indústria fotovoltaica.

Por meio da Lei no 18.112/2015 do Município de Recife, também instituiu o programa "Telhado Verde", que determina "a instalação de 'telhado verde' e a construção de reservatórios de acúmulo ou de retardo do escoamento das águas pluviais para a rede de drenagem" (Recife, 2015).

Também cria a obrigatoriedade de os imóveis comerciais e residenciais a providenciarem cobertura com vegetação verde apropriada, de preferência nativa, com a finalidade de melhorar "o aspecto paisagístico, diminuir a ilha de calor, absorver parte do escoamento superficial e melhorar o microclima local", sem que haja incentivo fiscal e/ou tributário (Recife, 2015).

O programa pernambucano é inspirado na legislação francesa, que instituiu, na Cidade de Paris, no ano de 2014, norma que obrigou prédios comerciais a terem cobertura com plantas vivas e/ou placas fotovoltaicas.

As maiores vantagens dos telhados verdes são a retenção da água das chuvas e a filtragem das partículas suspensas no ar (fuligem), além da produção de energia solar, por meio da instalação de painéis fotovoltaicos, capazes de eliminar até $100 \%$ dos custos com energia elétrica para necessidades básicas indispensáveis a um imóvel residencial, comercial ou industrial, a exemplo da iluminação.

Na legislação pernambucana, verifica-se a existência de relação direta entre os objetivos normatizados e o detalhamento das medidas necessárias para a devida implementação prática dos projetos nelas constantes, inclusive, indicando quais medidas geram benefícios fiscais, detalhando a forma de concessão.

Já no caso da legislação paraibana, como visto na análise precedente, por meio de duas leis que passaram a viger no ano de 2016, foram instituídas políticas de fomento à utilização de energia solar e eólica, sem que fossem concedidos benefícios fiscais e tributários para o segundo modelo e sem que nenhuma exposição de motivos fosse apresentada, sequer figurando dentre os artigos que trataram do crédito presumido em ICMS.

De tal modo, além das disposições gerais do texto legislativo paraibano já ensejar o maior beneficiamento do modelo fotovoltaico, a parte dispositiva da Lei no 10.720/2016 sacramenta o preterimento do modelo eólico, apenas estendendo os benefícios fiscais e tributários para os estabelecimentos industriais que adquirirem energia elétrica de fonte renovável solar, criando nefasta lacuna legislativa em relação ao incentivo que se intentava fomentar ao modelo de geração/utilização energética pautada nos ventos (Paraíba, 2016b).

Resta evidenciado, portanto, que estas leis paraibanas se afiguram demasiadamente genéricas e de fragilizado incentivo multigênero (econômico, fiscal/tributário, ecológico/ambiental), o que faz com que as políticas públicas voltadas ao setor energético renovável, no estado, enfrentem dificuldades multifatoriais.

É possível listar obstáculos que dificultam diretamente o processo de implementação de políticas públicas em larga escala no Estado da Paraíba. Além de o setor de geração e também de aproveitamento de energia elétrica advinda de fontes renováveis possuir pouca regulamentação por meio de legislação própria (Estadual e/ou Municipal), as políticas públicas decorrentes de Lei contemplam benefícios fiscais/tributários de dificultosa implementação.

As supra tratadas legislações estaduais paraibanas (Leis nos 10.718/2018 e 10.720/2016), por exemplo, visam ao fomento e à utilização de energias renováveis solar e eólica. No entanto, sequer detalham o que seria tal fomento e utilização, apenas 
tracejando de forma rasa que o estado financiará ações, pesquisas e estudos para implementação prática, "preferencialmente da energia fotovoltaica". Ainda verifica-se a existência de contradição em relação ao seu resultado finalístico, eis que, apesar de dispor acerca da concessão de benefícios fiscais para estabelecimentos industriais que utilizarem energia elétrica decorrente de fontes solar e eólica, apenas confere o incentivo tributário, através dos créditos de ICMS, em benefício da modalidade fotovoltaica.

\section{Considerações finais}

Em face de todo o exposto, restou evidenciado que a legislação nacional contempla termos excessivamente genéricos, fragilizando a capacidade das regulamentações estaduais e municipais para delimitar seus objetivos finalísticos, bem como a concessão de estímulos fiscais e tributários. Como visto, as políticas públicas voltadas ao setor de geração renovável, no Estado da Paraíba, ilustra bem tal constatação.

À exceção dos programas de menor escala, como exemplo da criação do Curso de Graduação em Engenharia de Energias Renováveis, pelo Centro de Energias Alternativas e Renováveis (CEAR/UFPB) e a criação e implementação de tecnologias ligadas às energias renováveis através do Centro de Ciências Exatas e da Natureza (CCEN) e do Programa de Pós-Graduação em Desenvolvimento e Meio Ambiente (PRODEMA/UFPB), que fornecem forte apoio à pesquisa e ao desenvolvimento das tecnologias energéticas com viés sustentável, são inúmeras as dificuldades enfrentadas pelo setor de energias renováveis quando o foco é a implementação de políticas públicas em maior espectro de abrangência.

São diversos os obstáculos enfrentados pelo setor energético renovável quanto ao processo de implementação de políticas públicas, em larga escala, no Estado da Paraíba. Há pouca regulamentação própria acerca da geração e do aproveitamento da energia elétrica oriunda de fontes renováveis e as políticas públicas, instituídas através de legislação própria, não traçam diretrizes claras e suficientes à implementação prática de incentivos fiscais e tributários nelas inseridos.

As Leis nos 10.718/2016 e 10.720/2016, do Estado da Paraíba, promoveram o estímulo à geração e a utilização de energia elétrica através das matrizes renováveis solar e eólica. Contudo, os parâmetros traçados não possuem comandos objetivos. A legislação descreve a ação estatal de forma genérica, ao pontuar que o Estado financiará ações, pesquisas e estudos quanto à geração e ao uso de energias renováveis, dando preferência à energia fotovoltaica, sem que delimitasse, por meio de que programa(s), ou projeto(s), como estas ações seriam implementadas.

$\mathrm{Na}$ sequência, as leis paraibanas estabelecem a concessão de benefícios fiscais e tributários para estabelecimentos industriais que fizerem uso de energia elétrica proveniente de fontes renováveis solar e eólica. Contudo, o trecho legal destinado a determinar a forma com que o benefício seria implementado, no caso, através de créditos presumidos de ICMS, apenas contempla o modelo fotovoltaico, relegando a presença e a importância da matriz eólica à parte programática da norma, sem que medida concreta e/ou estímulo fiscal fosse destinado à energia dos ventos.

Não se afigura razoável elencar eventual falta de primor técnico-legislativo para justificar a ausência de incentivos fiscais/tributários ao modelo eólico. Talvez a existência de entraves no setor ainda dificultem o incentivo financeiro governamental, especialmente face à notória predominância da utilização do modelo fotovoltaico no Estado da Paraíba, tanto em relação à captação, quanto ao aproveitamento da energia gerada através desta tecnologia.

No entanto, apesar de a energia elétrica decorrente da geração eólica não contar com incentivo financeiro decorrente das legislações estaduais objeto e análise, ainda há regulamentação normativa acerca do incentivo à pesquisa e ao desenvolvimento desse modelo de geração de energia elétrica pautado no uso dos ventos, o que pode ensejar a 
difusão de parcerias público-privadas voltadas para o desenvolvimento e a utilização das tecnologias de geração e de utilização de energia elétrica através de fontes renováveis, ainda que sem legislação específica.

Frisa-se que a ausência de marco legislativo específico acerca de determinada matéria, apesar de refletir a ausência formal do Estado em fornecer estímulos, dentre outros, financeiros, não torna as perspectivas regulamentares travadas para o setor que necessite se desenvolver. No caso das energias renováveis, por tratar-se de setor que envolve tecnologia de ponta e que envolve alto custo em sua cadeira de produção, atrelada à velocidade com que necessita de atualização, torna ainda mais árduo o processo de inserção nas políticas públicas das diversas esferas de poder.

Ponto chave é a constante apresentação de projetos focados na implementação das tecnologias renováveis à rotina diária das empresas e também do cidadão. Especialmente ao apresentar soluções técnico e ecologicamente eficientes e de custo financeiro reduzido. Nesse sentido, as Universidades e Institutos Federais desenvolvem papel primordial através das pesquisas que resultam em diversos projetos que promovem a melhoria do setor energético renovável, além da intensa geração de patentes.

Por fim, faz-se necessário o registro de que existe um forte elo entre a implementação prática de uma medida, a normatização da matéria envolvida e a demonstração da necessidade social. Cabe a sociedade, portanto, estimular o poder público a cuidar adequadamente dos interesses da coletividade.

\section{Conflito de interesses}

Os autores declaram não haver conflito de interesses.

\section{Referências}

Brasil. Resolução Normativa ANEEL no 482, de 17 de abril de 2012. Estabelece as condições gerais para o acesso de microgeração e minigeração distribuída aos sistemas de distribuição de energia elétrica, o sistema de compensação de energia elétrica, e dá outras providências. Disponível em: <http://www.amazonasenergia.com/cms/wpcontent/uploads/2020/01/RESOLUÇÃO-NORMATIVA-482-DE-2012-BIP-JUNHO2012.pdf>. Acesso em: 15 abr. 2020.

Brasil. Agência Nacional de Energia Elétrica. Resolução Normativa ANEEL no 687, de 24 de novembro de 2015. Altera a Resolução Normativa no 482, de 17 de abril de 2012, e os Módulos 1 e 3 dos Procedimentos de Distribuição - PRODIST. Disponível em: <http://www.bioenergiaengenharia.com.br/RESOLUCAO NORMATIVA REN 687_2015.pdf>. Acesso em: 15 abr. 2020.

Brasil. Constituição da República Federativa do Brasil de 1988. Disponível em: <http://www.planalto.gov.br/ccivil_03/constituicao/constituicao.htm>. Acesso em: 15 abr. 2020.

Brasil. Lei no 13.755, de 10 de dezembro de 2018. Estabelece requisitos obrigatórios para a comercialização de veículos no Brasil; institui o Programa Rota 2030 - Mobilidade e Logística; dispõe sobre o regime tributário de autopeças não produzidas; e altera as Leis no 9.440 , de 14 de março de 1997, 12.546, de 14 de dezembro de 2011, 10.865, de 30 de abril de 2004, 9.826, de 23 de agosto de 1999, 10.637, de 30 de dezembro de 2002, 8.383, de 30 de dezembro de 1991, e 8.989, de 24 de fevereiro de 1995, e o Decreto-Lei no 288, de 28 de fevereiro de 1967. Disponível em: <http://www.planalto.gov.br/ ccivil_03/_Ato2015-2018/2018/Lei/L13755.htm>. Acesso em: 15 abr. 2020. 
Brasil. Lei no 12.187, de 29 dezembro de 2009. Institui a Política Nacional sobre Mudança do Clima-PNMC e dá outras providências. Disponível em: <http://www.planalto.gov.br/ccivil_03/_Ato2007-2010/2009/Lei/L12187.htm>. Acesso em: 20 abr. 2020.

Brasil. Medida provisória no 843 de 2018. Estabelece requisitos obrigatórios para a comercialização de veículos no Brasil, institui o Programa Rota 2030 - Mobilidade e Logística e dispõe sobre o regime tributário de autopeças não produzidas. 2018b. Disponível em: <https://www.congressonacional.leg.br/materias/medidas-provisorias//mpv/133866>. Acesso em: 03 abr. 2020.

Brasil. Ministério de Minas e Energia, Empresa de Pesquisa Energética. Plano Decenal de Expansão de Energia 2030. Brasília: MME/EPE, 2007. Disponível em: <http://www.mme.gov.br/web/guest/secretarias/planejamento-e-desenvolvimentoenergetico/publicacoes/matriz-energetica-nacional-2030>. Acesso em: 14 abr. 2020.

Brasil. Projeto de Lei do Senado no 107 de 2017. Modifica o art. 2o da Lei no 10.848 , de 15 de março de 2004, que dispõe sobre a comercialização de energia elétrica, altera as Leis nos 5.655, de 20 de maio de 1971, 8.631, de 4 de março de 1993, 9.074, de 7 de julho de 1995, 9.427, de 26 de dezembro de 1996, 9.478, de 6 de agosto de 1997, 9.648, de 27 de maio de 1998, 9.991, de 24 de julho de 2000, 10.438, de 26 de abril de 2002, e dá outras providências, para incluir, no ambiente de contratação regulada, processos licitatórios de energia elétrica produzida em empreendimentos com mais de um tipo de fonte renovável de geração. Disponível em: <https://www25.senado.leg.br/web/atividade/materias//materia/128825/pdf>. Acesso em: 20 abr. 2020.

Carvalho Filho, J. S. Manual de Direito Administrativo. 23. ed. Rio de Janeiro: Lumen Juris, 2010.

Carvalho, L. S. Respostas à crise de 2008, uma análise do Brasil e da China. Revista Pesquisa e Debate, v. 31, n. 1, p. 232-264, 2019.

CEIRI NEWS. Global Energy Interconnection: a resposta da China para o aquecimento global. 2018. Disponível em: <https://ceiri.news/global-energy-interconnection-aresposta-da-china-para-o-aquecimento-global/>. Acesso em: 26 dez. 2019.

Colaferro, L. Energia Solar no Brasil: um panorama para [você] entender tudo. BlueSol Energia Solar, 2018. Disponível em: <https://blog.bluesol.com.br/energia-solar-no-brasilpanorama/>. Acesso em: 24 abr. 2020.

EUR-LEX. Para uma energia segura, a preços acessíveis e sustentável: pacote União da energia. 2015. Disponível em: <https://eur-lex.europa.eu/legal-content/PT/TXT/ ?uri=legissum:1801_7>. Acesso em: 17 nov. 2019.

FBDS - Fundação Brasileira para o Desenvolvimento Sustentável. Estudo sobre energias renováveis. 2018. Disponível em: <http://www.fbds.org.br/todasasmaterias.php3? id_rubrique=5>. Acesso em: 27 ago. 2019.

Hinrichs, R. A.; Kleinbach, M.; Reis, L. B. Energia e meio ambiente. 5 ed. São Paulo: Cengage Learning, 2014.

Paraíba. Lei no 10.718, de 22 de junho 2016. Dispõe sobre a obrigatoriedade de instalação de sistemas de captação de energia solar na construção de novos prédios, centros comerciais e condomínios residenciais, neste Estado. Disponível em: <https://www.legisweb.com.br/legislacao/?id=325187>. Acesso em: 14 abr. 2020. 
Paraíba. Lei no 10.720, de 22 de junho de 2016. Institui a Política Estadual de Incentivo à Geração e Aproveitamento da Energia Solar e Eólica no Estado da Paraíba e dá outras providências. João Pessoa, PB: 2016b. Disponível em: <https://www.legisweb.com.br/ legislacao/?id=328750 . . Acesso em: 14 abr. 2020.

Pernambuco. Decreto no 39.460/2013. Regulamenta a concessão e a utilização do crédito presumido do ICMS previsto no Programa de Sustentabilidade na Atividade Produtiva do Estado de Pernambuco - PESUSTENTAVEL, instituído pela Lei no 14.666 , de 18 de maio de 2012. Disponível em: <https://www.sefaz.pe.gov.br/Legislacao/Tributaria/ Documents/Legislacao/Decretos/2013/Dec39460_2013.htm>. Acesso em: 22 abr. 2020.

Pernambuco. Lei no 14.666/2012. Cria o Programa de Sustentabilidade na Atividade Produtiva do Estado de Pernambuco - PESUSTENTÁVEL. Disponível em: <https://www.sefaz.pe.gov.br/Legislacao/Tributaria/Documents/legislacao/Leis_Tributa rias/2012/Lei14666_2012.htm>. Acesso em: 22 abr. 2020.

Portal Solar. Energia solar vai impulsionar aumento do mercado de carros elétricos. 2019. Disponível em: <https://www.portalsolar.com.br/blog-solar/energia-solar/energia-solarvai-impulsionar-aumento-do-mercado-de-carros-eletricos.html>. Acesso em: 05 abr. 2020.

Recife. Lei no 18.112 de 2015. Dispõe sobre a melhoria da qualidade ambiental das edificações através da obrigatoriedade de instalação do "telhado verde", e construção de reservatórios de acúmulo ou de retardo do escoamento das águas pluviais para a rede de drenagem e dá outras providências. Disponível em: <https://www.legisweb.com.br/ legislacao/?id=280138>. Acesso em: 14 abr. 2020.

UFPB - Universidade Federal da Paraíba. Resolução CONSEPE no 16/2015. Disponível em: <http://www.prg.ufpb.br/prg/codesc/documentos/legislacao/rsep16_2015.pdf/ view>. Acesso em: 14 abr. 2020.

Informação da Licença: Este é um artigo Open Access distribuído sob os termos da Licença Creative Commons Attribution, que permite uso irrestrito, distribuição e reprodução em qualquer meio, desde que a obra original seja devidamente citada. 